\title{
Towards a new therapeutic target: Helicobacter pylori flavodoxin
}

\author{
Nunilo Cremades ${ }^{1,2}$, Marta Bueno ${ }^{1,2}$, Miguel Toja ${ }^{3} \&$ Javier Sancho $^{1,2}$ \\ ${ }^{1}$ Biocomputation and Complex Systems Physics Institute \\ ${ }^{2}$ Departamento de Bioquímica y Biología Molecular y Celular. Facultad de Ciencias. \\ Universidad de Zaragoza. 50009-Zaragoza (Spain) \\ ${ }^{3}$ Operon S.A. Cuarte de Huerva. Zaragoza. Spain
}




\section{ABSTRACT}

Helicobacter pylori flavodoxin is the electronic acceptor of the piruvateoxidoreductase complex (POR) that catalyzes piruvate oxidative decarboxilation. Inactivation of this metabolic route precludes bacterial survival. Because flavodoxin is not present in the human host, substances interfering electronic transport from POR might be well suited for

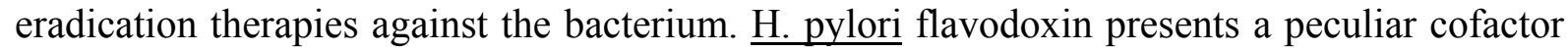
(FMN) binding site, compared to other known flavodoxins, where a conserved aromatic residue is replaced by alanine. A cavity thus appears under the cofactor that can be filled with small organic molecules. We have cloned $\underline{H}$. pylori fldA gene, expressed the protein in Escherichia coli and characterized the purified flavodoxin. Thermal up-shift assays of flavodoxin with different concentrations of benzylamine, as well as fluorescence titration experiments indicates benzylamine binds in the pocket near the FMN binding site. It seems thus that low affinity inhibitors of $\underline{H}$. pylori flavodoxin can be easily found that, after improvement, may give rise to leads.

Keywords: small molecule binding, Helicobacter pylori, flavodoxin, drug design, protein stability, protein cavity, 


\section{INTRODUCTION}

For most of the twentieth century, ulcers were thought to be caused by stress and dietetic factors but, in 1982, a link was established between a bacterium, Helicobacter pylori,

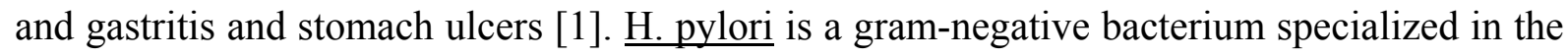
colonisation of the human stomach, a unique ecological niche characterized by a very acidic

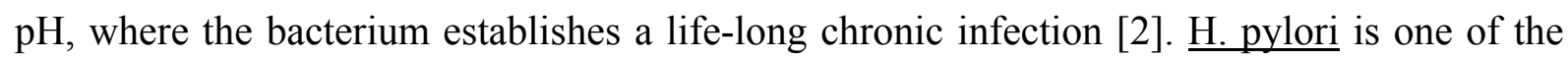
most common human pathogens and it has been detected in 50\% of the world population [3]. Most infected people are, however, asymptomatic, and only 20\% develop severe gastroduodenal pathologies, including type B gastritis, stomach and duodenal ulcers [4], adenocarcinomas [5] and stomach lymphomas [6]. Discovery of the genetic variability of $\underline{H}$. pylori [7] sheds light on this unexpected finding and suggests that if antibiotics are used extensively, the target bacterium is likely to develop resistance [8]. The current treatment consists of a triple [9], sometimes quadruple therapy, combining a proton inhibitor and two (or three) antibiotics. New cases of resistance are continuously reported [10-13] and, therefore, new treatments need to be developed [14-16]. Efforts to find a human vaccine against $\underline{H}$. pylori [17-19] encounter difficulties characteristic of the reported genetic variability. Looking for new molecular targets to develop new drugs against the pathogen [20] is, thus, an obvious goal.

Towards that end, we notice that the $\underline{H}$. pylori genome contains a small redox protein,

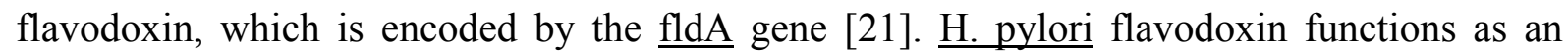
electron acceptor of the pyruvate-oxidoreductase (POR) enzyme complex, which catalyses the oxidative decarboxilation of pyruvate [22]. Pyruvate is an important intermediate in the physiology of the bacterium as it constitutes a branch point of several metabolic routes [23]. Recent work has reported the crystal structure of $\underline{H}$. pylori flavodoxin and has demonstrated that both, flavodoxin and the POR complex, are essential for bacterium survival [24]. A 
second requirement for the new molecular target should be its absence in the human host. Flavodoxins have been identified in both prokaryotes [25] and eukaryotes [26] but not in mammals, where flavodoxin-like domains are found as part of larger proteins such as P450 reductase [27]. Besides, the flavodoxin has been proposed to play a potencial role in the pathogenesis of MALT lymphoma, being detected in the sera of a high percentage of patients with MALToma compared to patients with other diseases related with $\underline{H}$. pylori [28]. Flavodoxin thus, seems a promising candidate to be a target to develop drugs suited for the eradication of the bacterium.

Our laboratory has used over the years the flavodoxin from a different specie (Anabaena PCC7119) as a model protein to investigate protein stability, protein folding and binding [29-35]. From the structural point of view, flavodoxins are $\alpha / \beta$ proteins and bind, at the C-terminal end of the $\beta$-sheet, a molecule of flavin mononucleotide (FMN) that confers redox properties to the protein [36]. The redox potentials of FMN are drastically altered by the protein environment, making possible the one-electron reduction of the cofactor, which is essential for protein function. The different flavodoxins are usually classified in two groups: short-chain flavodoxin (with around 150 residues) and long-chain flavodoxin (with an

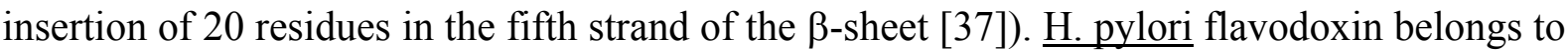
the long-chain group, like that from Anabaena. The two proteins share a $43 \%$ sequence identity (Fig. 1a). Although the overall fold of $\underline{\mathrm{H}}$. pylori flavodoxin is similar to that of other known flavodoxin, its FMN binding site is peculiar (Fig. 1b) because it contains, in one of the cofactor binding loops, an alanine residue where a vast majority of flavodoxins display an aromatic residue, typically a tryptophan. This makes the FMN of $\underline{H}$. pylori flavodoxin partly accessible to solvent through a pocket at the protein surface where small molecules could bind and inhibit protein function, and thus, bacterium growth. The inhibitory effect could be exerted either by modifying the environment of the FMN and thus, altering the redox 
potentials [38] or simply, if the ligand is bulky enough, by interfering with flavodoxin recognition by the POR partner complex. We begin here, exploring this possibility by testing the binding of small molecules to the pocket near the FMN binding site in $\underline{H}$. pylori flavodoxin.

\section{EXPERIMENTAL}

\section{DNA isolation, and PCR amplification of the fldA gene}

Total genomic DNA was isolated from three different $\underline{H}$. pylori antigen-positive stool samples and three negative matched controls using QIAamp DNA Stool Mini Kit (Qiagen). $\underline{\text { H. pylori antigen status was ascertained by ELISA, using Premier Platinum Stool Antigen }}$ detection test $\underline{\mathrm{HpSA}}$, and by immunochromatography using Immunocard STAT HpSA (Meridian Diagnostics, Inc.). Then, the $\underline{H}$. pylori flavodoxin DNA coding sequence was amplified by PCR, using the Nco-5'Primer: GGATTGAGCATATGGGAAAAATTGG and the BamHI 3'primer: CTAACAATGAAGGATCCAATTCTAG. Both primers were derived from the directly submitted J99 fldA sequence (accession number AF221524 [39]) obtained from the Genebank (EMBL) database. The reaction mixture $(50 \mu 1)$ contained undigested chromosomal DNA, $1 \mu \mathrm{g}$; primers, $50 \mathrm{ng}$; dNTP mixture, $2 \mathrm{mM}$; 10-fold-concentrated amplification buffer, $5 \mu 1$ and Taq DNA polymerase (Madgen), 1.5 units. Thirty-five cycles of 2 minutes hybridization at $44^{\circ} \mathrm{C}, 1$ minute extension at $72^{\circ} \mathrm{C}$ and 1 minute denaturation at $94^{\circ} \mathrm{C}$ were performed. After amplification, fragments of approximately 600 nucleotides were identified in two $\underline{H}$. pylori positive amplifications, corresponding to the predicted 613 nucleotides fragment. The fragments were gel-purified and cloned into the NcoI-BamHI sites of the pET28a expression vector (Novagen) using standard techniques. Several clones were obtained in E. coli JM109, sequenced and used for protein expression. 


\section{Recombinant overexpression and purification of $\underline{H}$. pylori flavodoxin}

E. coli expression strain BL21 containing the pET28a-fldA plasmid was grown in 10 $\mathrm{ml}$ of Luria-Bertani medium in the presence of $0.2 \mathrm{mg}$ kanamycine. The culture was diluted 10 -fold in the same conditions and cells were grown to an absorbance of 0.8 at $600 \mathrm{~nm}$. At this point, isopropyl $\beta$-D-thiogalactoside (IPTG) was added to a final concentration of $1 \mathrm{mM}$ and the cells were allowed to grow for at least $3 \mathrm{~h}$ and then pelleted and washed once with $0.15 \mathrm{M} \mathrm{NaCl}$. After centrifugation, the cells were dissolved in $50 \mathrm{mM}$ Tris-HCl buffer, $\mathrm{pH} 8$, containing $1 \mathrm{mM} \quad \beta$-mercaptoethanol, $1 \mathrm{mM} \quad$ EDTA and $1 \mathrm{mM}$ PMSF (phenylmethanesulphonyl fluoride). The cells were disrupted by ultrasonic treatment (four periods of $45 \mathrm{~s}$, with $30 \mathrm{~s}$ intervals). Debris and unbroken cells were removed by centrifugation (45 min at $18000 \mathrm{rpm}$ at $4{ }^{\circ} \mathrm{C}$ ). Then, the supernatant was precipitated with $65 \%\left(\mathrm{NH}_{4}\right)_{2} \mathrm{SO}_{4}$ as first step of purification.

After precipitation with $65 \%$ saturated $\left(\mathrm{NH}_{4}\right)_{2} \mathrm{SO}_{4}$, the remaining supernatant was poured onto a DE-52 DEAE-cellulose column equilibrated with $65 \%$ saturated $\left(\mathrm{NH}_{4}\right)_{2} \mathrm{SO}_{4}$ in

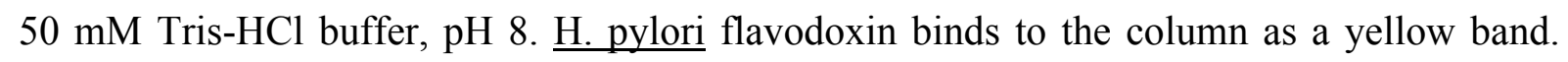
The protein was eluted with a reverse gradient of the equilibration buffer from $65 \%$ to $0 \%$ $\left(\mathrm{NH}_{4}\right)_{2} \mathrm{SO}_{4}$ saturation. After dialysis, flavodoxin fractions were poured onto a DE-52 DEAEcellulose column previously equilibrated with $50 \mathrm{mM}$ Tris- $\mathrm{HCl}$ buffer, $\mathrm{pH} 8$. A nearly pure flavodoxin was eluted with a linear gradient of 0 to $0.5 \mathrm{M} \mathrm{NaCl}$ in $50 \mathrm{mM}$ Tris- $\mathrm{HCl}$ buffer, $\mathrm{pH}$ 8. Finally the protein was concentrated in a MonoQ10 column (FPLC, Amersham) equilibrated with $50 \mathrm{mM}$ Tris- $\mathrm{HCl}$ buffer, $\mathrm{pH} 8$, and then eluted with a linear gradient of 0 to $1 \mathrm{M} \mathrm{NaCl}$. The protein was pure according to SDS-PAGE and to the ratio of UV to visible absorbance.

In addition, the Anabaena flavodoxin W57A mutant, where the highly conserved tryptophan residue of the FMN binding site is substituted by alanine, was expressed and 
purified as described [30].

\section{Determination of extinction coefficients}

The extinction coefficient of $\underline{H}$. pylori flavodoxin in the fully oxidized state was determined as described by Mayhew and Massey [40] using, for released FMN, a corrected extinction coefficient at $445 \mathrm{~nm}$ of $12020 \mathrm{M}^{-1} \mathrm{~cm}^{-1}$, in $10 \mathrm{mM}$ phosphate buffer $\mathrm{pH} 7$ and of $12070 \mathrm{M}^{-1} \mathrm{~cm}^{-1}$, in $50 \mathrm{mM}$ TRIS-HCl $\mathrm{pH}$ 8. All extinction coefficients, as well as the correction factor, were determined in triplicate. Determination of its extinction coefficient shows quite similar values at different conditions. The extinction coefficient (at $25 \pm 0.1{ }^{\circ} \mathrm{C}$ ) at $452 \mathrm{~nm}$ is of $10650 \mathrm{M}^{-1} \mathrm{~cm}^{-1}$ in $50 \mathrm{mM}$ TRIS-HCl buffer $\mathrm{pH} 8$ and of $10490 \mathrm{M}^{-1} \mathrm{~cm}^{-1}$ in 10 mM phosphate buffer $\mathrm{pH} 7$.

\section{Spectroscopic Characterization}

UV/Visible absorbance; UV/Visible fluorescence emission; far-UV, near-UV and visible circular dichroism (CD) measurements were carried out at $25 \pm 0.1{ }^{\circ} \mathrm{C}$ and $\mathrm{pH} 7.0$ in $10 \mathrm{mM}$ phosphate buffer. The UV/Vis spectra were recorded in a Uvikon $942 \mathrm{UV}-\mathrm{Visible}$ spectrophotometer from Kontron Instruments. Fluorescence emission spectra (300 to $400 \mathrm{~nm}$ ) were recorded, with excitation at $280 \mathrm{~nm}$, using an Aminco-Bowman Series 2 spectrometer. Fluorescence emission spectra, in the visible region (from 500 to $600 \mathrm{~nm}$ ) were also recorded with excitation at $453 \mathrm{~nm}$. CD spectra in the near-, far-UV and visible were recorded in a Jasco 710 spectropolarimeter. All experiments were carried out in darkness.

\section{Thermal up-shift assay}

Thermal denaturation was followed by recording FMN fluorescence emission (525 $\mathrm{nm}$, with excitation at $453 \mathrm{~nm}$ ) in an Aminco-Bowman Series 2 Spectrometer. Protein concentration was $10 \mu \mathrm{M}$ in $10 \mathrm{mM}$ phosphate buffer, $\mathrm{pH} 7$.

Thermal denaturation curves were fitted to a two-state equation: 


$$
\mathrm{S}=\frac{\mathrm{S}_{\mathrm{N}}+m_{\mathrm{N}} \mathrm{T}+\left(\mathrm{S}_{\mathrm{U}}+m_{\mathrm{U}} \mathrm{T}\right) \exp ^{-\Delta G(\mathrm{~T}) / \mathrm{RT}}}{1+\exp ^{-\Delta G(\mathrm{~T}) / \mathrm{RT}}}
$$

where $S_{N}$ and $S_{U}$ represent the spectroscopic signals of the native and unfolded states at $0 \mathrm{~K}$, and $m_{\mathrm{N}}$ and $m_{\mathrm{U}}$ are the temperature dependences of those signals. The Gibbs energy function, $\Delta G(\mathrm{~T})$, is given as:

$$
\Delta G(\mathrm{~T})=\Delta H_{\mathrm{Tm}}\left(1-\mathrm{T} / \mathrm{T}_{\mathrm{m}}\right)-\Delta C_{p}\left(\left(\mathrm{~T}_{\mathrm{m}}-\mathrm{T}\right)+\mathrm{T} \ln \left(\mathrm{T} / \mathrm{T}_{\mathrm{m}}\right)\right)
$$

with $\Delta C_{p}$ and $\Delta H_{\mathrm{Tm}}$ being the unfolding heat capacity and enthalpy changes at $\mathrm{T}_{\mathrm{m}}$, respectively. Fitting thermal unfolded curves to equation (1) provides accurate values of $T_{m}$, reasonable $\Delta H_{\mathrm{Tm}}$ values and usually unreliable $\Delta C_{p}$ values. It should be noticed that, although the visible fluorescence thermal unfolding of the protein can be fitted to two-state model, the

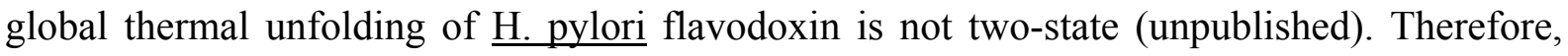
the reported $\mathrm{T}_{\mathrm{m}}$ values are apparent.

In order to carry out the thermal up-shift assay, flavodoxin denaturations were performed in absence and in presence of different concentrations of ligand (after 14h of equilibration). The ligand binding affinity was estimated from the change induced by the ligand in the unfolding transition temperature. First, fluorescence emission unfolding curves recorded in both absence and presence of ligand were fitted to Eq.(1) and the corresponding thermodynamic parameters obtained. Then, the ligand binding constant at the apparent melting temperature $\left(K_{\mathrm{Tm}}\right)$ was calculated using the expression described by Brandts and Lin [41]: 


$$
K_{\mathrm{Tm}}=\frac{\exp \left[\frac{-\Delta H_{\mathrm{u}}}{\mathrm{R}}\left(\frac{1}{\mathrm{~T}_{\mathrm{m}}}-\frac{1}{\mathrm{~T}_{0}}\right)+\frac{\Delta C p_{\mathrm{u}}}{\mathrm{R}}\left(\ln \frac{\mathrm{T}_{\mathrm{m}}}{\mathrm{T}_{0}}+\frac{\mathrm{T}_{0}}{\mathrm{~T}_{\mathrm{m}}}-1\right)\right]}{\left[\mathrm{L}_{\mathrm{Tm}}\right]}
$$

where $\Delta H_{\mathrm{u}}$ and $\Delta C p_{\mathrm{u}}$ are, respectively, the unfolding enthalpy and heat capacity changes at the melting temperature in the absence of ligand, $T_{0}$ and $T_{m}$ the melting temperatures in absence and presence of ligand, $R$ the ideal gas constant and $\left[\mathrm{L}_{\mathrm{Tm}}\right]$ the concentration of free ligand at $\operatorname{Tm}\left(\left[\mathrm{L}_{\mathrm{Tm}}\right] \cong[\mathrm{L}]_{\text {tot }}\right.$ when $\left.[\mathrm{L}]_{\mathrm{tot}}>>[\text { Protein }]_{\text {tot }}\right)$. To compare the binding affinities obtained from thermal up-shift assays with those derived from the ligand titrations, the $K_{\mathrm{Tm}}$ values have to be extrapolated to the titration temperature. For that, we use the expression suggested by Pantoliano et al. [42]:

$$
K_{\mathrm{T}}=K_{\mathrm{Tm}} \exp \left[\frac{-\Delta H}{\mathrm{R}}\left(\frac{1}{\mathrm{~T}}-\frac{1}{\mathrm{~T}_{\mathrm{m}}}\right)\right]
$$

where $\Delta H^{\mathrm{T}} \mathrm{L}$ is the binding enthalpy at the temperature $\mathrm{T}$.

\section{Dissociation Constants}

Dissociation constants of the flavodoxin-ligand complexes were directly determined by titration, followed fluorometrically (excitation was at $464 \mathrm{~nm}$, and the emission was recorded at $525 \mathrm{~nm}$ ) in an Aminco-Bowman Series 2 Spectrometer at $25 \pm 0.1{ }^{\circ} \mathrm{C}$ (in darkness). Protein samples were prepared by mixing $900 \mu$ ligand solution of different concentrations with $100 \mu \mathrm{l}$ aliquots of $40 \mu \mathrm{M}$ holoprotein, in $10 \mathrm{mM}$ sodium phosphate, $\mathrm{pH}$ 7.0 and were allowed to equilibrate for $14 \mathrm{~h}$. Ligand binding, presumably at the pocket of the FMN binding site, quenches the cofactor fluorescence emission. The dissociation constants were calculated using Origin 6.0 (OriginLab Co.) by fitting the emission fluorescence data to equation: 


$$
\mathrm{F}=\mathrm{F}_{\mathrm{p}}+\frac{\left(\mathrm{F}_{\mathrm{c}}-\mathrm{F}_{\mathrm{p}}\right)}{2 \mathrm{C}_{\mathrm{p}}}\left(\mathrm{C}_{\mathrm{p}}+\mathrm{C}_{\mathrm{L}}+K_{\mathrm{d}}-\sqrt{\left(\mathrm{C}_{\mathrm{p}}+\mathrm{C}_{\mathrm{L}}+K_{\mathrm{d}}\right)^{2}-4 \mathrm{C}_{\mathrm{p}} \mathrm{C}_{\mathrm{L}}}\right)+\mathrm{BC}_{\mathrm{L}}
$$

where $\mathrm{F}$ is the observed fluorescence emission intensity of each solution, $\mathrm{F}_{\mathrm{p}}$ the emission of the protein, $\mathrm{F}_{\mathrm{c}}$ the emission of the complex, $\mathrm{C}_{\mathrm{p}}$ the total protein concentration, $K_{\mathrm{d}}$ the dissociation constant of the complex in micromolar units, $\mathrm{C}_{\mathrm{L}}$ the total concentration of ligand in each solution, and $\mathrm{B}$ a constant (to fit the experimental final slope at high ligand concentrations). The robustness of the fits is indicated by the fact that the total concentration of protein, when treated as unknown, was correctly predicted (within 90\%).

\section{RESULTS AND DISCUSSION}

\section{Cloning, overexpression and purification}

The $\underline{H}$. pylori fldA gene was amplified using PCR. To design the oligonucleotides, the information available in the Genebank (EMBL) for $\underline{\text { H. pylori }}$ J99 strain was used. Two oligonucleotides, complementary to the beginning and to the end of the fldA gene, bearing $\underline{\text { NcoI }}$ and $\underline{B a m H I}$ restriction sites were synthesized. After amplification, a single band of approximately 600 nucleotides (Fig. 2) was identified.

The protein was purified to homogeneity from a bacterial extract using three anion exchange chromatography steps. Denaturant gel electrophoresis analysis revealed one major band with a molecular weight of $18 \mathrm{kDa}$ (data not shown), which is in agreement with the expected value of $17.9 \mathrm{kDa}$.

\section{Spectroscopic properties of $\underline{H}$. pylori holoflavodoxin}

Helicobacter pylori holoflavodoxin displays a characteristic absorbance spectrum in the visible (Fig. 3a) due to the bound FMN cofactor, with maxima at $378 \mathrm{~nm}$ and $452 \mathrm{~nm}$. The 
near UV maximum is at $271 \mathrm{~nm}$. The main near-ultraviolet and visible absorbance properties

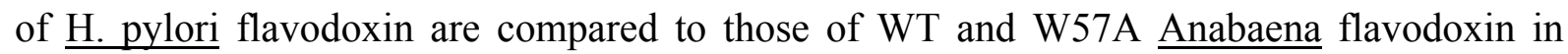
Table 1. We noticed that mutation of the Anabaena W57 residue to alanine does not make the

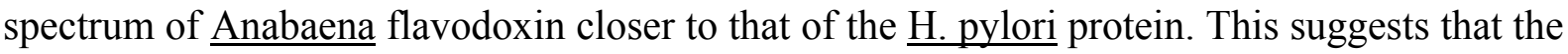

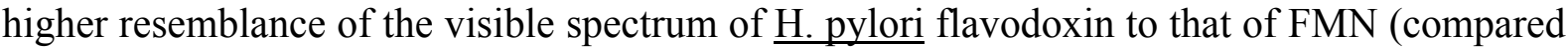
to that of Anabaena flavodoxin) in not related to the lack of a tryptophan residue at the FMN

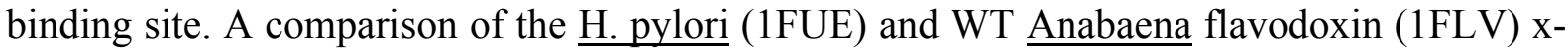
ray structures does not offer clues for the differences in visible spectrum of the two flavodoxins, because both the tyrosine/FMN stacking and the hydrogen bonding pattern are similar. However, solvent-accessible surface calculation indicates that the FMN in the $\underline{\mathrm{H}}$. pylori flavodoxin is far more accessible to water molecules, that in other long-chain flavodoxins (160 $\AA^{2}$ for $\underline{H}$. pylori flavodoxin and between 99 and $109 \AA^{2}$ for the others [24]). This fact could explain the observed resemblance between the H. pylori flavodoxin and FMN spectra.

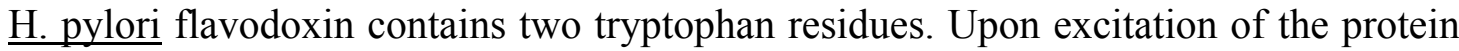
at $280 \mathrm{~nm}$, the maximum fluorescence emission in native conditions $\left(25^{\circ} \mathrm{C}\right)$ appears at 322 nm (Fig. 3b). This indicates that tryptophans are shielded from the solvent in the folded conformation, as can be observed in the x-ray structure. Heating the protein to $90{ }^{\circ} \mathrm{C}$ leads to a shift of the fluorescence emission maximum to $344 \mathrm{~nm}$, indicative of partial unfolding. The fluorescence spectrum in the visible region is shown in Fig. 3c. Upon unfolding, the FMN is released and the quantum yield increases moderately. This moderate increase agrees with the fact that, unlike in other flavodoxins where the FMN is largely shielded from solvent (as is

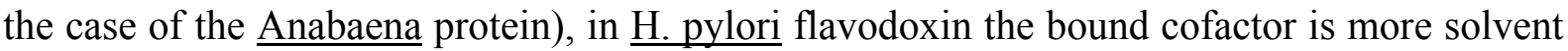
exposed and thus less quenched by protein residues.

The far-UV CD spectrum of flavodoxin in $10 \mathrm{mM}$ phosphate $\mathrm{pH} 7.0$, is shown in Fig. 
3d. The ellipticity minimum at $222 \mathrm{~nm}$ is consistent with a substantial amount of secondary structure, which is largely, but not completely, lost upon heating to $90{ }^{\circ} \mathrm{C}$. The spectrum is similar to that of the Anabaena flavodoxin where, in addition to secondary structure contributions, there are also contributions from aromatic residues. It should be noticed, in this respect, that the two proteins contain highly conserved clusters of aromatic residues.

The near-UV CD spectrum (Fig. 3e) shows distinct peaks, as is characteristic of a well-defined tertiary structure. The peaks are lost upon heating. This spectrum differs from that of Anabaena holoflavodoxin (unpublished) by having a very pronounced negative peak centred at $268 \mathrm{~nm}$.

The visible CD spectrum (Fig. 3f) was recorded to further characterise the binding of the flavin mononucleotide $(\mathrm{FMN})$ to the protein at $25{ }^{\circ} \mathrm{C}$. The protein-induced asymmetric environment of FMN is lost upon heating.

\section{Thermal stability of Holoflavodoxin}

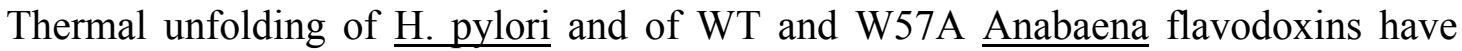
been carried out to compare the thermal stability of the proteins. The fluorescence emission of the FMN in the visible region increases as a consequence of the unfolding. The fluorescence curves (Fig. 4) have been fitted to two-state models and apparent $\mathrm{T}_{\mathrm{m}}$ have been calculated.

The melting temperatures obtained from the thermal profiles were $317 \mathrm{~K}$ for $\underline{\mathrm{H}}$. pylori, $328 \mathrm{~K}$ for the Anabaena W57A mutant and $340 \mathrm{~K}$ for Anabaena WT flavodoxin. The stability rises in this series mimic the increase in the affinity of the three apoflavodoxin-FMN complexes, which for the Anabaena WT is around $3 \mathrm{kcalmol}^{-1}$ higher than for the W57A

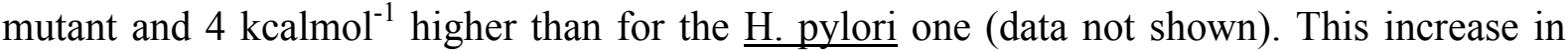
complex stability is expected, because any ligand that specifically binds the native state of a protein should stabilize it [43].

\section{Small molecule Binding}




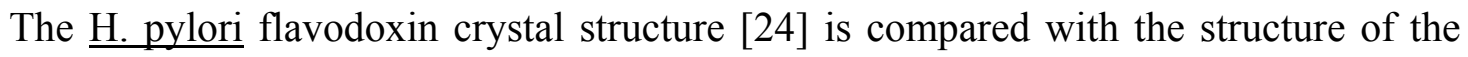
flavodoxin from the cyanobacteria Anabaena PCC7119 in Fig. 1a. Although the overall fold is conserved, there is an interesting difference at the FMN binding site. Usually, as in Anabaena flavodoxin, the isoalloxacine ring of FMN is embedded into the protein, stacked between two hydrophobic residues. All structurally known flavodoxins display a tyrosine residue at the re- and a tryptophan one at the si-face of the FMN molecule (except the Clostridium beijerenckii flavodoxin, with a methionine at the si- and a tryptophan at the reface). This aromatic environment is a well-conserved feature of the FMN binding site that is altered in $\underline{H}$. pylori flavodoxin, where the si-face is occupied by an alanine. As a consequence, the isoalloxacine ring is slightly rotated, compared to other flavodoxins, although, this doesn't affect the hydrogen-bonding pattern of the cofactor. The absence of the indole group of the tryptophan, replaced by alanine, at the si-face of the FMN in $\underline{\mathrm{H} \text {. pylori }}$ flavodoxin creates a pocket in the vicinity of the cofactor. This makes the FMN group more accessible to solvent and yet, water molecules have not been found in the pocket in the crystal structure. Hence, small molecules could, in principle, bind in this pocket and inhibit protein function (either causing redox potential changes or, if bulky enough, through sterical constrains suppressing interactions with its partner protein) leading to inhibition of bacterial growth.

Work currently in progress in our laboratory, has focused on the binding of small molecules to cavity-containing mutants of Anabaena flavodoxin. Our unpublished results indicated that, when the FMN is removed, its binding site can bind small ligands. For the $\underline{\mathrm{H}}$. pylori flavodoxin, we suspected that we could probably detect binding to the functional holoform by taking advantage of the pocket at the FMN site. We thus tested some small ligands and present here the results of benzylamine binding, a compound that combines the aromatic features of the missing binding site tryptophan with the possibility of establishing 
cation/ $\pi$ interactions with the FMN [44].

First we tested binding of benzylamine to the W57A Anabaena mutant flavodoxin and observed marked quenching of FMN fluorescence in the presence of the ligand. The concentration dependence of the quenching (Fig. 5a) is consistent with complex formation. The binding seems to occur close to the FMN, as indicated by the quenching. Calculation of the dissociation constant by ligand titration gave a value around $4 \mathrm{kcalmol}^{-1}$ for the benzylamine Anabaena W57A complex. When the binding of benzylamine to $\underline{\mathrm{H} \text {. pylori }}$ flavodoxin was tested, we also found a marked quenching and the calculated binding of energy was around $3 \mathrm{kcalmol}^{-1}$ (Table 3).

To confirm benzylamine binding, we performed thermal up-shift assays. These assays measure ligand binding dependent protein stabilization, as monitored by $T_{m}$ measurements of the melting transitions of ligand-protein complexes, and of the uncomplexed protein. Protein stabilization by ligand binding is related to ligand binding affinity ( $\left.\Delta G_{\text {bind }}\right)$ because of the thermodynamic linkage between the binding and unfolding equilibria [45-46].

As shown in Table 2, thermal up-shift assays can detect ligand binding. Small and negative $T_{m}$ shifts are detected for the wild type Anabaena holoflavodoxin that should be attributed either to binding to non native conformations or to effects exerted through modifying water structure. In contrast the thermal melting transition of $\underline{H}$. pylori flavodoxin was increased by 5 degrees in the presence of $50 \mathrm{mM}$ benzylamine, while in the Anabaena W57A mutant, the shift was only of $2 \mathrm{~K}$.

The calculation of binding constants, from thermal denaturation data, is based on two assumptions: all transitions are two-state in character, and ligands bind only to the nature state with a 1:1 stoichiometry [41]. All the parameters needed to calculate dissociation constants at $298 \mathrm{~K}$ are taken from the fits of the unfolding curves. The ligand binding enthalpy is the only parameter not experimentally determined from thermal melting transitions. For a majority of 
ligand /protein binding enthalpy measurements reported in the literature, however, an average near to $-10 \mathrm{kcalmol}^{-1}$ to $-15 \mathrm{kcalmol}^{-1}$ has been observed [47-48]. In the absence of any other information, we assume that $-15 \mathrm{kcal}_{\mathrm{mol}}{ }^{-1}$ can be used to make reasonable estimates of $K_{\mathrm{T}}$ [42].

No binding constant can be calculated for Anabaena WT because of the negative shift observed in the melting transition temperature. Binding energies obtained by thermal shift assays agree well with those obtained by direct equilibrium methods (as titration) when they are extrapolated to identical temperature $\left(-3.8 \mathrm{kcalmol}^{-1}\right.$ and $-3.9 \mathrm{kcalmol}^{-1}$, respectively $)$ for Anabaena W57A (Table 3). Nonetheless, for $\underline{H}$. pylori there is some difference between the energies calculated by titration $\left(-2.7 \mathrm{kcalmol}^{-1}\right)$ and by thermal denaturation $\left(-4.2 \mathrm{kcalmol}^{-1}\right)$, posibly due to the uncertainty in the estimated enthalpy of ligand binding.

\section{H. pylori flavodoxin as a new drug target}

The genetic diversity of the $\underline{H}$. pylori species is large. Simultaneous infection with

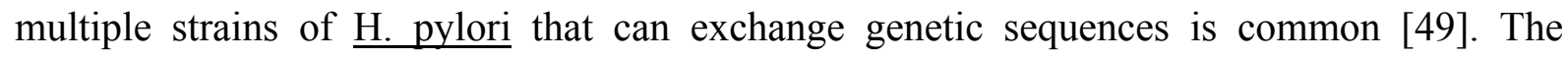
development of clinically manifest disease during chronic infection seems to result from complex and poorly understood interactions among a number of factors, including the susceptibility of the host and the virulence of the infecting strains [50].

Triple therapy has been the most successful method for eradicating $\underline{H}$. pylori (eradication rate of $80-90 \%$ ). However, increasing metronidazole resistance has limited the expansion of this therapy [51]. The activation of metronidazole, inside the bacteria, is closely linked to the oxidation of pyruvate [52] and requires reduction of the nitro group of nitroimidazole to generate the entity that kills susceptible bacteria. In aerobic conditions, this reduction is mediated by the POR complex. Electrons liberated in the oxidation of pyruvate, are first transferred to flavodoxin, from where they can be delivered to metronidazole. The short-lived reaction products formed can react with DNA, causing strand breaking and 
subsequent cell death [53].

The problem associated to metronidazole resistance could be avoided by focusing on new targets. One obvious possibility is to block $\underline{H}$. pylori electron transfer reactions at the flavodoxin level. Ligand binding near the FMN flavodoxin cofactor could easily disrupt electron transfer either by altering the redox potentials or by impeding the recognition of the POR-complex (which most likely will take place near the FMN site). Since the surface exposed region of the cofactor binding site is small and highly conserved among the flavodoxins of different species and, additionally, it constitutes the binding site of partner flavodoxin proteins, we hope inhibitors designed to bind there should resist genetic variability. Our preliminary study indicates that it is not difficult to identify small molecules, such as benzylamine, which bind to the $\underline{H}$. pylori pocket, and thus may constitute leads towards inhibiting flavodoxin function. As the affinity of these molecules may be low, known methods of redesigning ligands for higher affinity will be needed [45].

\section{ACKNOWLEDGEMENTS}

Spanish Ministry of Education Fellowhips supported NC and MB. We thank L.A. Campos and A. Velázquez for stimulating discussion. We acknowledge financial support from grants BCM2001-252 (DGI, Spain) and P120/2001 (DGA, Spain). 


\section{REFERENCES}

[1] J.R. Warren and B.J. Marshall, Unidentified curved bacilli on gastric epithelium in active chronic gastritis, Lancet 1 (1983) 1273-1275.

[2] R.A. Feldman, In: Helicobacter pylori: Molecular and Cellular Biology, ed. M. Achtman and S. Suerbaum, Epidemiologic observations and open questions about disease and infection caused by Helicobacter pylori, (Horizon Scientific, Norfolk, 2001).

[3] J. Parsonnet, The incidence of Helicobacter pylori infection, Aliment. Pharmacol. Ther. 9 suppl. 2 (1995) 45-51.

[4] M.J. Blaser, Hypotheses on the patogenesis and natural history of Helicobacter pyloriinduced inflammation, Gastroenerology 102 (1992) 720-727.

[5] J. Parsonnet, G.D. Friedman, D.P. Vandersteen, Y. Chang, J.H. Vogelman, N. Orentreich and R.K. Sibley, Helicobacter pylori infection and the risk of gastric carcinoma, N. Engl. J. Med. 325 (1999) 1127-1131.

[6] A.C Wotherspoon, C. Doglioni, T.C. Diss, L. Pan, A. Moschini, M. de Boni and P.G. Isaacson, Regression of primary low-grade B-cell gastric lymphoma of mucosa-associated lymphoid tissue type after eradication of Helicobacter pylori, Lancet 342 (1993) 575-577.

[7] D.E. Taylor, M. Eaton, N. Chang and S.M. Salama, Construction of a Helicobacter pylori genome map and demonstration of diversity at the genome level, J. Bacteriol. 174 (1992) 6800-6806.

[8] Y. Glupczynski and A. Burette, Drug therapy for Helicobacter pylori infection: problems and pitfalls, Am. J. Gastroenterol. 85 (1990) 1545-1551.

[9] K. Seppala and H. Nuutinen, New options in eradication of Helicobacter pylori, Ann. Med. 27 (1995) 601-604.

[10] S. Mendonca, C.C. Ecclissato, M.S. Sartori, A.P. Godoy, R.A. Guersoni, M. Deguer and J. Pedrazzoli, Prevalence of Helicobacter pylori resistance to metronidazole, clarithromycin, 
amoxycillin, tetracycline, and furazolidone in Brazil, Gastroenterology 118 Part 2 Suppl. 2 (2000) 5822.

[11] J.J. Kim, R. Reddy, S.G. Reddy, F.A. El-Zaatari, M.S. Osato, J.G. Kim, D.Y. Graham and D.H. Kwon, Increasing Helicobacter pylori resistance to metronidazole, clarithromycin and tetracycline, Gastroenterology 118 Part 1 Suppl. 2 (2000) 2671.

[12] R.J. Adamek, S. Suerbaum, B. Pfaffenbach and W. Opferkuch, Primary and acquired Helicobacter pylori resistance to clarithromycin, metronidazole, and amoxicillin - Influence on treatment outcome, Am. J. Gastroenterol. 93 (1998) 386-389.

[13] F. Megraud, Helicobacter pylori resistance to antibiotics, Presse Med. 26 (1997) 17751780.

[14] F. Megraud, Resistance of Helicobacter pylori to antibiotics: the main limitation of current proton-pump inhibitor triple therapy, Eur. J. Gastroen. Hepat. 11 Suppl. 2 (1999) S35S37.

[15] F. Megraud, J. Laurent, J.F. Flejou, A. Caekaert and P. Barthelemy, Helicobacter pylori resistance to antimicrobial agents after treatment failure with omeprazole triple therapy, Gastroenterology 116 Part 2 (1999) G0519.

[16] K. Murakami, T. Fujioka, T. Kubota, R. Sato, M. Kodama, M. Kimoto and M. Nasu, Prevalence of acquired Helicobacter pylori resistance to clarithromycin and combinations of eradication regimens, Gastroenterology 116 Part 2 (1999) G1138.

[17] M.F.T. Rupnow, R.D. Shachter, D.K. Owens and J. Parsonnet, Quantifying the population impact of a prophylactic Helicobacter pylori vaccine, Vaccine 20 (2001) 879-885. [18] J.S. Kim, J.H. Chang, S.I. Chung and J.S. Yum, Importance of the host genetic background on immune responses to Helicobacter pylori infection and therapeutic vaccine efficacy, FEMS Immunol. Med. Mic. 31 (2001) 41-46.

[19] C. Hatzifoti, Helicobacter pylori vaccine strategies - triggering a gut reaction, Trends. 
Immunol. 22 (2001) 225.

[20] P. Legrain and D. Strosberg, Protein interaction domain mapping for the selection of validated targets and lead compounds in the anti-infectious area, Curr. Pharm. Des. 8 (2002) 1189-1198.

[21] R.A. Alm, L.S. Ling, D.T. Moir, B.L. King, E.D. Brown, P.C. Doig, D.R. Smith, B. Noonan, B.C. Guild, B.L. deJonge, G. Carmel, P.J. Tummino, A. Caruso, M. Uria-Nickelsen, D.M. Mills, C. Ives, R. Gibson, D. Merberg, S.D. Mills, Q. Jiang, D.E. Taylor, G.F. Vovis, and T.J. Trust, Genomic-sequence comparison of two unrelated isolates of the human gastric pathogen Helicobacter pylori, Nature 397 (1999)176-180.

[22] N.J. Hughes, C.L. Clayton, P.A. Chalk and D.J. Kelly, Helicobacter pylori porCDAB and oorDABC genes encode distinct pyruvate:flavodoxin and 2-oxoglutarate:acceptor oxidoreductases which mediate electron transport to NADP, J. Bacteriol. 180 (1998) 11191128.

[23] P. Kaihovaara, J. Hook-Nikanne, M. Uusi-Oukari, T.U. Kosunen and M. Salaspuro, Flavodoxin-dependent pyruvate oxidation, acetate production and metronidazole reduction by Helicobacter pylori, J. Antimicrob. Chemother. 41 (1998) 171-177.

[24] J. Freigang, K. Diederichs, K.P. Schafer, W. Welte and R. Paul, Crystal structure of oxidized flavodoxin, an essential protein in Helicobacter pylori, Protein Sci. 11 (2002) 253261.

[25] C. Osborne, L.M. Chen and R.G. Matthews, Isolation, cloning, mapping, and nucleotide sequencing of the gene encoding flavodoxin in Escherichia coli, J. Bacteriol. 173 (1991) $1729-1737$.

[26] S. Wakabayashi, T. Kimura, K. Fukuyama, H. Matsubara and L.J. Rogers, The amino acid sequence of a flavodoxin from the eukaryotic red alga Chondrus crispus, Biochem. J. 263 (1989) 981-984. 
[27] E.E. Scott, Y.A. He, M.R. Wester, M.A. White, C.C. Chin, J.R. Halpert, E.F. Johnson, and C.D. Stout, An open conformation of mammalian cytochrome P450 2B4 at 1.6-A resolution, Proc. Natl. Acad. Sci. U S A. 100 (2003) 13196-13201.

[28] C.S. Chang, L.T. Chen, J.C. Yang, J.T Lin, K.C. Chang and J.T. Wang, Isolation of a Helicobacter pylori protein, FldA, associated with mucosa-associated lymphoid tissue lymphoma of the stomach, Gastroenterology 117 (1999) 82-88.

[29] C.G. Genzor, A. Beldarrain, C. Gomez-Moreno, J.L. Lopez-Lacomba, M. Cortijo and J. Sancho, Conformational stability of apoflavodoxin, Protein Sci. 5 (1996) 1376-1388.

[30] S. Maldonado, A. Lostao, M.P. Irun, J. Fernandez-Recio, C.G. Genzor, E.B. Gonzalez, J.A. Rubio, A. Luquita, F. Daoudi and J. Sancho, Apoflavodoxin: structure, stability, and FMN binding, Biochimie 80 (1998) 813-820.

[31] A. Lostao, C. Gomez-Moreno, S.G. Mayhew and J. Sancho J, Differential stabilization of the three FMN redox forms by tyrosine 94 and tryptophan 57 in flavodoxin from Anabaena and its influence on the redox potentials, Biochemistry 36 (1997) 14334-14344.

[32] A. Lostao, M. El Harrous, F. Daoudi, A. Romero, A. Parody-Morreale and J. Sancho, Dissecting the energetics of the apoflavodoxin-FMN complex, J. Biol. Chem. 275 (2000) $9518-9526$.

[33] J. Fernandez-Recio, C.G. Genzor and J. Sancho, Apoflavodoxin folding mechanism: an alpha/beta protein with an essentially off-pathway intermediate, Biochemistry 40 (2001) $15234-15245$.

[34] C.G. Genzor, A. Perales-Alcon, J. Sancho, and A. Romero, Closure of a tyrosine/tryptophan aromatic gate leads to a compact fold in apo flavodoxin, Nat. Struct. Biol. 3 (1996) 329-332.

[35] J.L. Casaus, J.A. Navarro, M. Hervas, A. Lostao, M.A. De la Rosa, C. Gomez-Moreno, J. Sancho and M. Medina, Anabaena sp. PCC 7119 flavodoxin as electron carrier from 
photosystem I to ferredoxin-NADP ${ }^{+}$reductase. Role of $\operatorname{Trp}(57)$ and $\operatorname{Tyr}(94)$, J. Biol. Chem. 277 (2002) 22338-22344.

[36] M.L. Ludwig, K.A. Pattridge, A.L. Metzger, M.M. Dixon, M. Eren, Y. Feng and R.P. Swenson, Control of oxidation-reduction potentials in flavodoxin from Clostridium beijerinckii: the role of conformation changes, Biochemistry 36 (1997) 1259-1280.

[37] S.G. Mayhew and M.L. Ludwig, Flavodoxins and electron transferring flavoproteins (Academic Press, New York, 1975).

[38] F.C. Chang and R.P. Swenson, Regulation of oxidation-reduction potentials through redox-linked ionization in the $\mathrm{Y} 98 \mathrm{H}$ mutant of the Desulfovibrio vulgaris [Hildenborough] flavodoxin: direct proton nuclear magnetic resonance spectroscopic evidence for the redoxdependent shift in the pKa of Histidine-98, Biochemistry 36 (1997) 9013-9021.

[39] D.H. Kwon, M.S. Osato, D.Y. Graham and F.A. El-Zaatari, Quantitative RT-PCR analysis of multiple genes encoding putative metronidazole nitroreductases from $\underline{\text { Helicobacter }}$ pylori, Int. J. Antimicrob. Agents. 15 (2000) 31-36.

[40] S.G. Mayhew and V. Massey, Purification and characterization of flavodoxin from Peptostreptococcus elsdenii, J. Biol. Chem. 244 (1969) 794-802.

[41] J.F. Brandts and L.N. Lin, Study of strong to ultratight protein interactions using differential scanning calorimetry, Biochemistry 29 (1990) 6927-6940.

[42] M.W. Pantoliano, E.C. Petrella, J.D. Kwasnoski, V.S. Lobanov, J. Myslik, E. Graf, T. Carver, E. Asel, B.A. Springer, P. Lane and F.R. Salemme, High-density miniaturized thermal shift assays as a general strategy for drug discovery, J. Biomol. Screen. 6 (2001) 429-440.

[43] T.T. Waldron and K.P.Murphy, Stabilization of proteins by ligand binding: application to drug screening and determination of unfolding energetics, Biochemistry 42 (2003) 50585064.

[44] J. Fernandez-Recio, A. Romero and J. Sancho, Energetics of a hydrogen bond (charged 
and neutral) and of a cation/pi interaction in apoflavodoxin, J. Mol. Biol. 290 (1999) 319-331.

[45] I. Luque and E. Freire, Structural parameterization of the binding enthalpy of small ligands, Proteins 49 (2002) 181-190.

[46] M.J. Todd and E. Freire, The effect of inhibitor binding on the structural stability and cooperativity of the HIV-1 protease, Proteins 36 (1999) 147-156.

[47] T. Wiseman, S. Williston, J.F. Brandts and L.N. Lin, Rapid measurement of binding constants and heats of binding using a new titration calorimeter, Anal. Biochem. 179 (1989) 131-137.

[48] A.E. Eriksson, W.A. Baase, J.A. Wozniak and B.M. Matthews BW, A cavity-containing mutant of T4 lysozyme is stabilized by buried benzene, Nature 355 (1992) 371-373.

[49] M. Kidd, A.J. Lastovica, J.C. Atherton and J.A. Louw, Heterogeneity in the Helicobacter pylori vacA and cagA genes, Gut. 45 (1999) 499-502.

[50] S.J. Spechler, L. Fischbach and M. Feldman, Clinical aspects of the genetic variability in Helicobacter pylori, J. A. M. A. 283 (2000) 1264-1266.

[51] H. Rautelin, K Seppala, O.V. Renkonen, U. Vainio and T.U. Kosunen, Role of metronidazole resistance in therapy of Helicobacter pylori infections, Antimicrob. Agents Chemother. 36 (1992) 163-166.

[52] D.I. Edwards, Nitroimidazole drugs--action and resistance mechanisms. I. Mechanisms of action, J. Antimicrob. Chemother. 31 (1993) 9-20.

[53] D.I. Edwards, Nitroimidazole drugs--action and resistance mechanisms. II. Mechanisms of resistance, J. Antimicrob. Chemother. 31 (1993) 201-210. 
Table 1. UV/VIS spectral properties of the different flavodoxins characterized

\begin{tabular}{lccccc}
\hline & \multicolumn{2}{c}{$\lambda_{\text {max }}(\mathbf{n m})$} & & & \multicolumn{2}{c}{$\lambda_{\text {min }}(\mathbf{n m})$} \\
\cline { 2 - 3 } \cline { 5 - 6 } Molecule & I & II & & I & II \\
\hline FMN & 445 & 372 & & 400 & 303 \\
H. pylori flavodoxin & 452 & 378 & & 406 & 310 \\
Anabaena WT flavodoxin & 463 & 374 & & 406 & 315 \\
Anabaena W57A flavodoxin & 460 & 373 & & 407 & 315 \\
\hline
\end{tabular}


Table 2. Thermal up-shift assays data

\begin{tabular}{|c|c|c|c|c|c|c|}
\hline \multirow[b]{2}{*}[\mathbf{L}]{$^{\mathrm{a}}$} & \multicolumn{2}{|c|}{ Anabaena WT } & \multicolumn{2}{|c|}{ Anabaena W57A } & \multicolumn{2}{|c|}{ Helicobacter pylori } \\
\hline & $\mathbf{T}_{\mathrm{m}}(\mathbf{K})^{\mathbf{b}}$ & $\Delta \mathbf{T}_{\mathrm{m}}(\mathbf{K})$ & $\mathbf{T}_{\mathbf{m}}(\mathbf{K})$ & $\Delta \mathbf{T}_{\mathrm{m}}(\mathrm{K})$ & $\mathbf{T}_{\mathrm{m}}(\mathbf{K})$ & $\Delta \mathbf{T}_{\mathrm{m}}(\mathbf{K})$ \\
\hline 0 & $340.1 \pm 0.1$ & & $328.5 \pm 0.0$ & & $317.4 \pm 0.2$ & \\
\hline 10 & $338.7 \pm 0.2$ & $-1.4 \pm 0.2$ & $329.6 \pm 0.1$ & $1.1 \pm 0.1$ & $319.8 \pm 0.1$ & $2.3 \pm 0.2$ \\
\hline 50 & $339.3 \pm 0.1$ & $-0.9 \pm 0.1$ & $330.1 \pm 0.0$ & $1.7 \pm 0.1$ & $322.2 \pm 0.1$ & $4.8 \pm 0.2$ \\
\hline
\end{tabular}

${ }^{\mathrm{a}}$ Benzylamine concentration in $\mathrm{mM}$

${ }^{\mathrm{b}}$ Calculated from fittings of flavodoxin thermal denaturation curves to a two-state model (equations 1 and 2). 
Table 3. Dissociation constants at $25^{\circ} \mathrm{C}$ calculated by titration and thermal up-shift assays

\begin{tabular}{|c|c|c|c|c|}
\hline \multirow[b]{2}{*}{ Protein } & \multicolumn{2}{|c|}{ Titration } & \multicolumn{2}{|c|}{ Thermal up-shift assay } \\
\hline & $K_{\mathrm{d}}^{\mathrm{a}}(\mathrm{mM})$ & $\Delta G(\mathrm{kcal} / \mathrm{mol})$ & $K_{d}^{b}(\mathbf{m M})$ & $\Delta G(\mathrm{kcal} / \mathrm{mol})$ \\
\hline Anabaena WT & $143.7 \pm 85.3$ & $-1.1 \pm 0.4$ & $\mathrm{Nd}^{\mathrm{c}}$ & $\mathrm{Nd}$ \\
\hline Anabaena W57A & $1.7 \pm 0.3$ & $-3.8 \pm 0.1$ & $1.2 \pm 0.5$ & $-3.9 \pm 0.2$ \\
\hline Helicobacter pylori & $9.8 \pm 1.3$ & $-2.7 \pm 0.1$ & $0.9 \pm 0.3$ & $-4.2 \pm 0.2$ \\
\hline
\end{tabular}

${ }^{\text {a }}$ Directly determined by fluorescence titration (excitation at $464 \mathrm{~nm}$, and emission at $525 \mathrm{~nm}$ ) using equation 5 .

${ }^{\mathrm{b}}$ Indirectly obtained from thermal up-shift assays (equation 3), extrapolating from binding constants calculated at the melting temperature (equation 4).

${ }^{\mathrm{c}}$ Not determined. 


\section{FIGURE LEGENDS}

Figure 1. (a) Helicobacter pylori flavodoxin structure (1FUE, in yellow) superimposed on the Anabaena PCC7119 flavodoxin structure (1FLV, in orange). (b) Surface accessibility of the cofactor binding site in: (right) Helicobacter pylori, (left) Anabaena sp. The absence of the indole group of the tryptophan residue creates a cavity in the protein that is only partially closed by the cofactor. FMN is represented in sticks. Positions in contact with the cofactor are

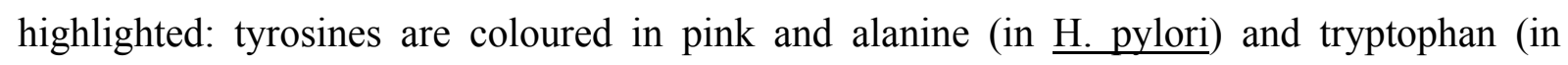

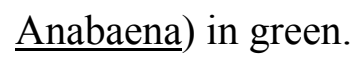

Figure 2. Ethidium bromide-stained agarose gel displaying the results of PCR amplification of $\underline{\text { fldA }}$ gene. In order to check the conditions of $\underline{H}$. pylori genomic DNA sample, amplification of a control gene codifying urease was carried out. Amplification without DNA was used as a negative control. The molecular weight marker used was $\phi X 174 /$ HaeIII ( $\underline{\text { Stratagene }})$. Arrows mark the product amplified.

Figure 3. Helicobacter pylori holoflavodoxin spectroscopic characterization. (a) UV/VIS absorbance of holo and apoflavodoxin. Spectral properties of the folded (tick line) and unfolded $\left(90{ }^{\circ} \mathrm{C}\right.$, thin line) protein measured with different techniques. (b) UV fluorescence emission. (c) Fluorescence emission in the visible region. (d) Far-UV circular dichroism. (e) Near-UV circular dichroism. (f) Circular dichroism in the visible region.

Figure 4. Thermal denaturation curves of flavodoxin as followed by fluorescence emission of FMN: Anabaena wild type (circles), Anabaena W57A (squares), Helicobacter pylori (triangles). Solid lines represent the fitting of the data to a two-state model. 
Figure 5. (a) Titration of FMN fluorescence with benzylamine in Anabaena WT (circles), $\underline{\text { Anabaena }}$ W57A (squares) and $\underline{H}$. pylori flavodoxin (triangles). Solid lines represent the fitting of the data to equation 3. (b) Thermal up-shift assays performed with $\underline{H}$. pylori flavodoxin in presence of increasing amounts of benzylamine: absence of ligand (grey squares); $10 \mathrm{mM}$ (blue triangles); and $50 \mathrm{mM}$ (red circles). The thermal curves were obtained following FMN fluorescence and then fitted to a two-state model. 
Figure 1

(a)

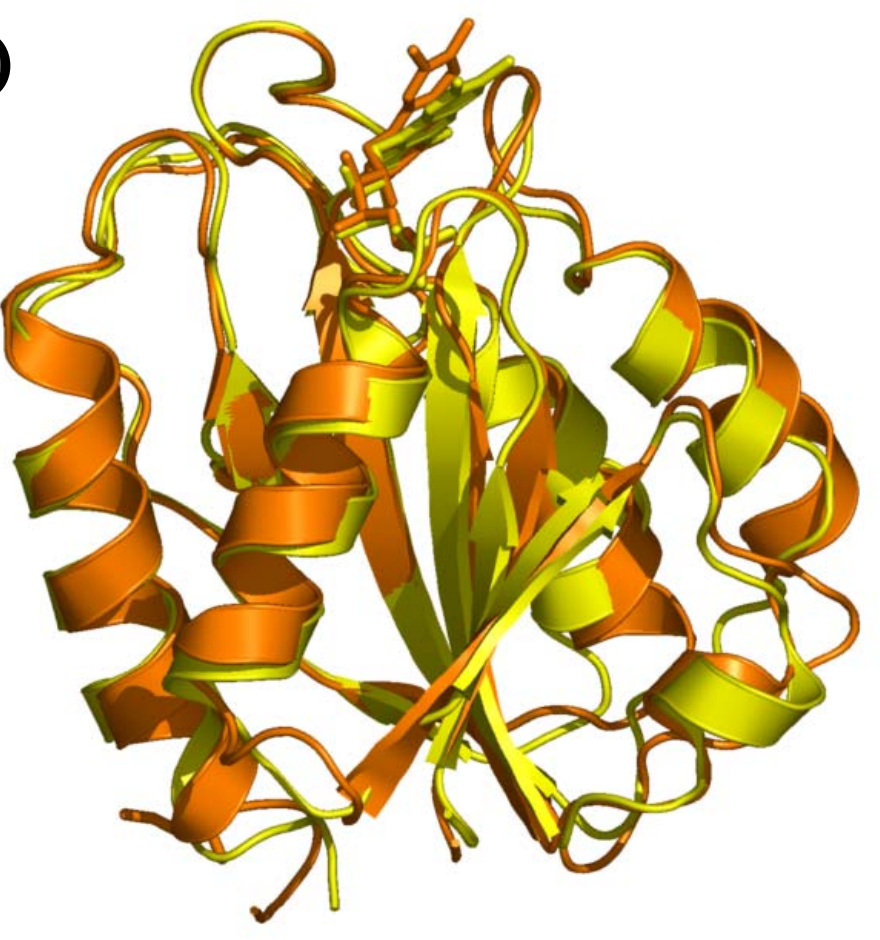

(b)

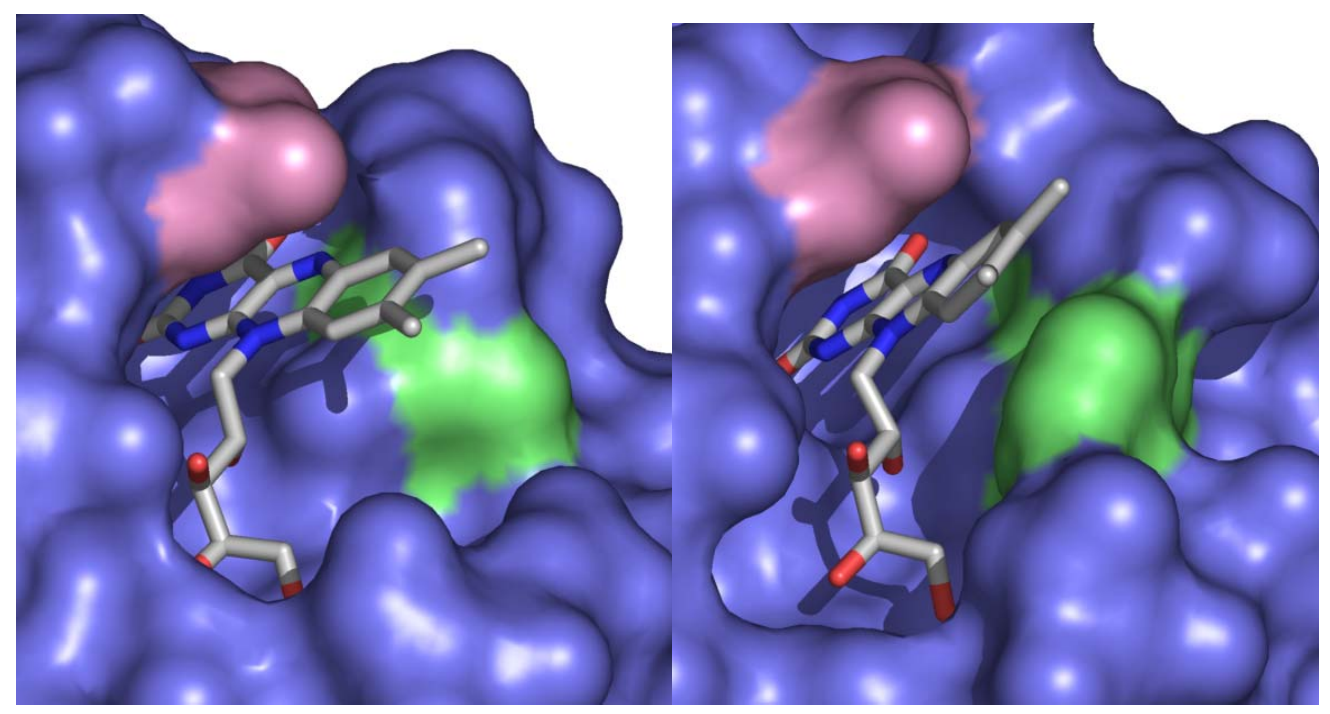


Figure 2

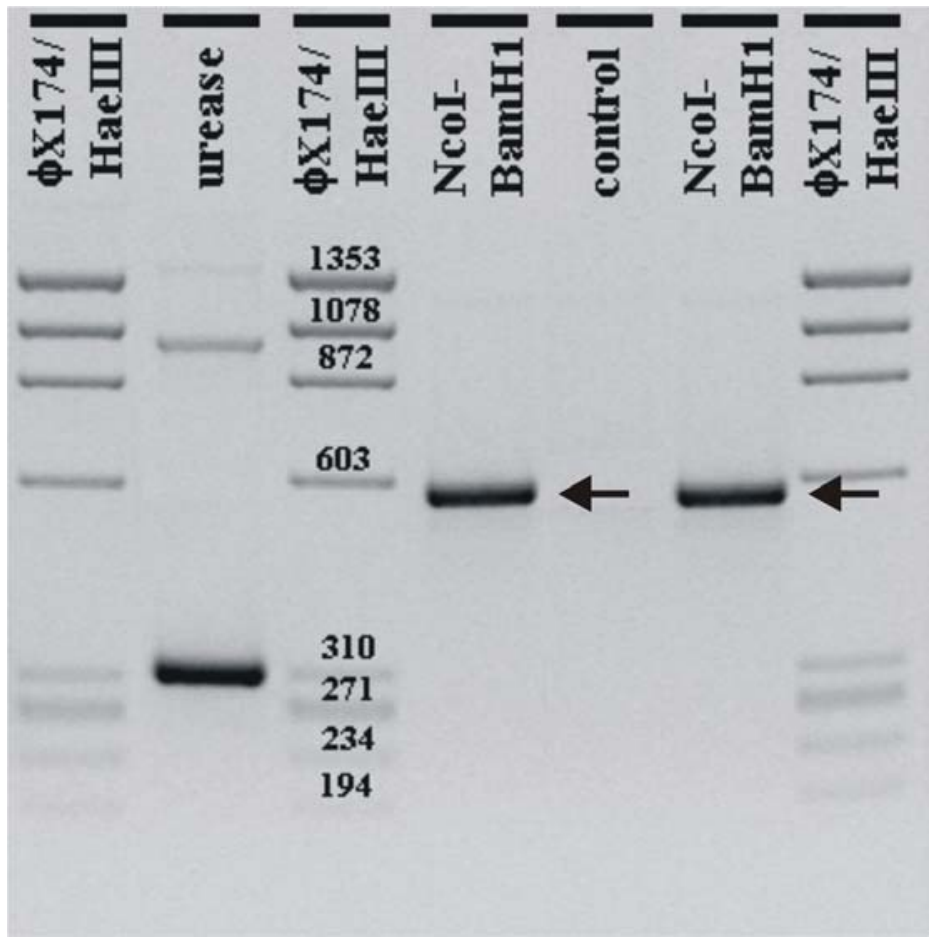


Figure3
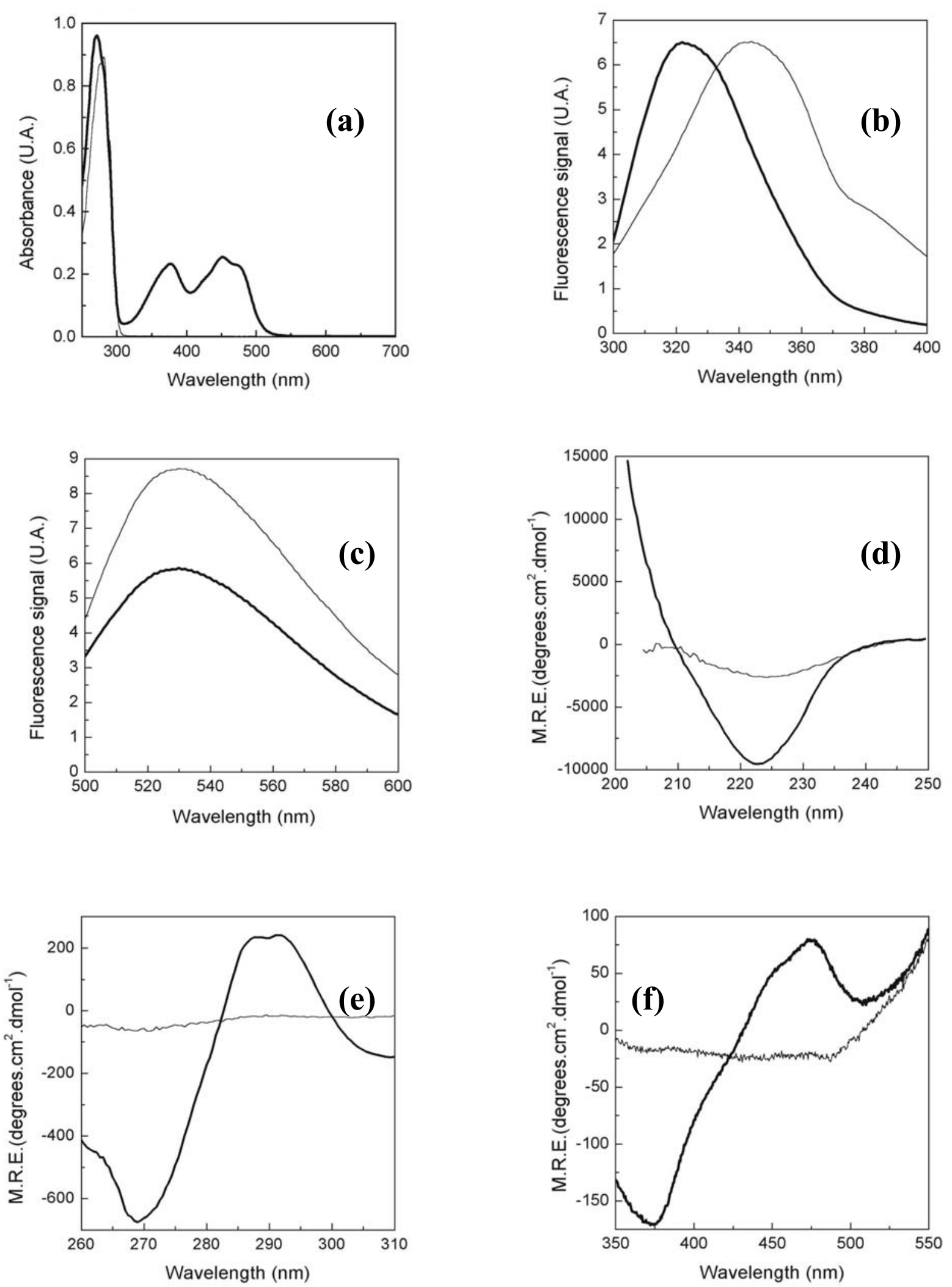
Figure 4

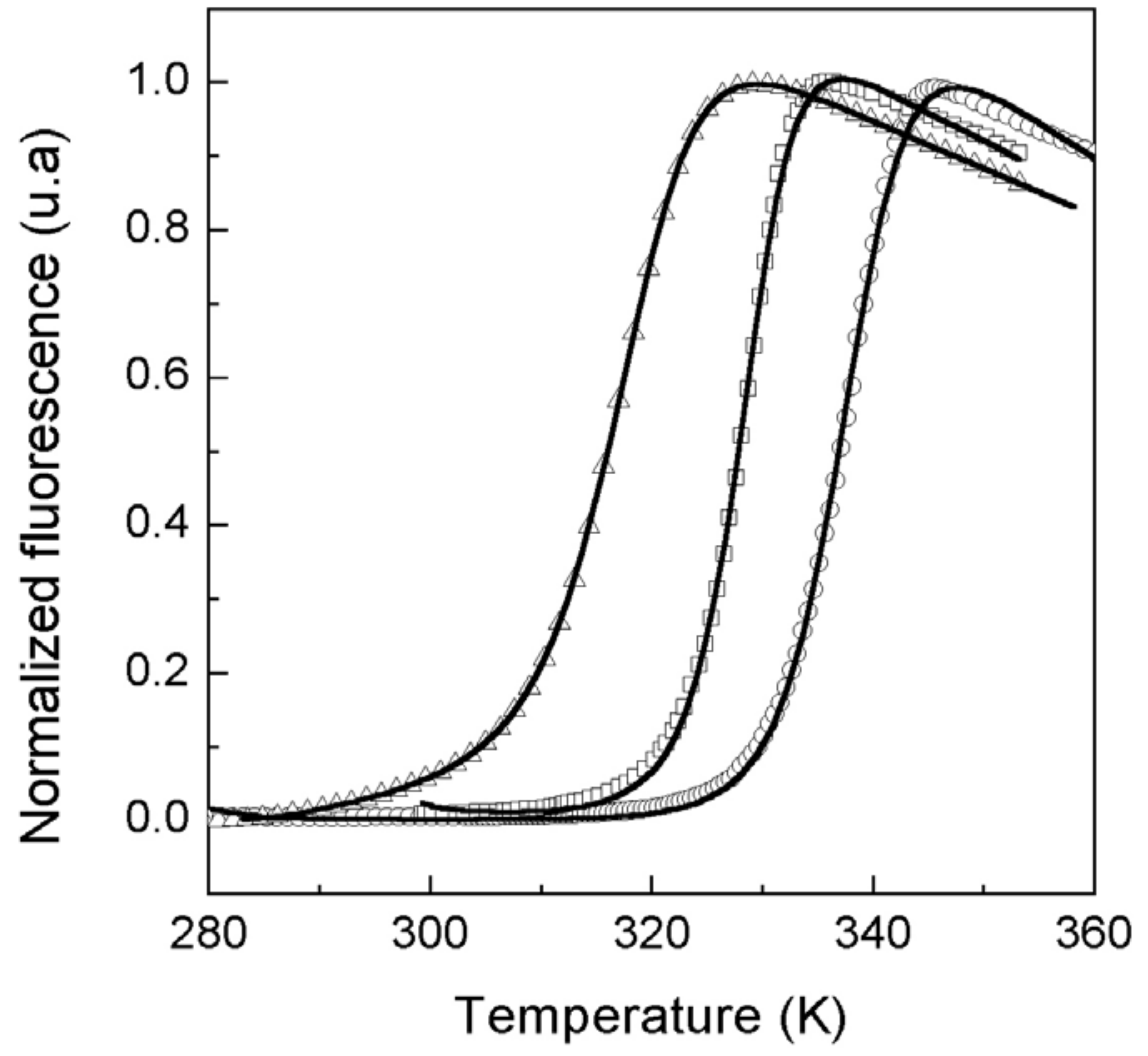


Figure 5

(a)

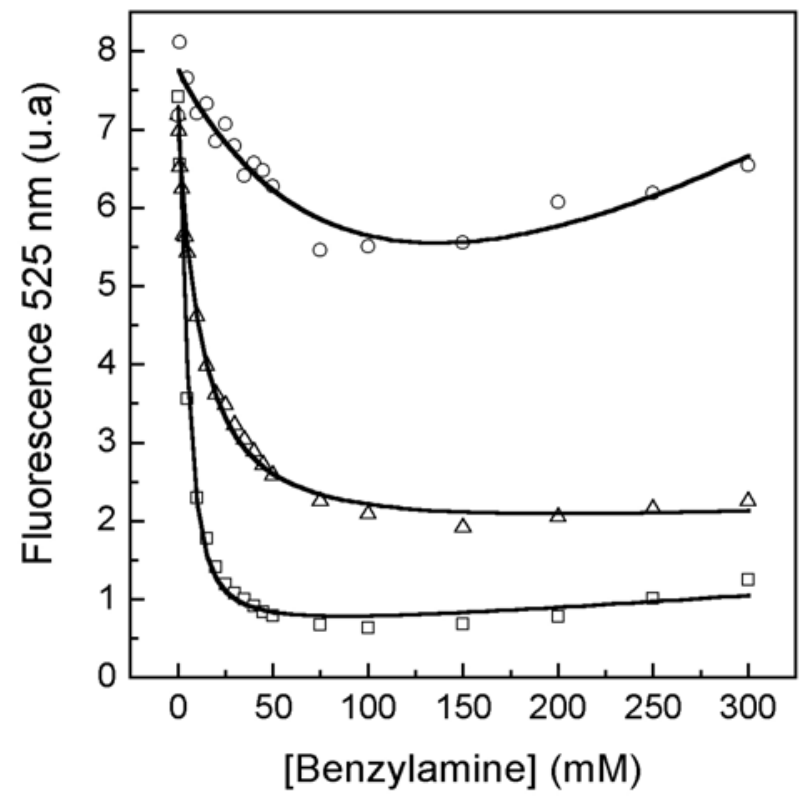

(b)

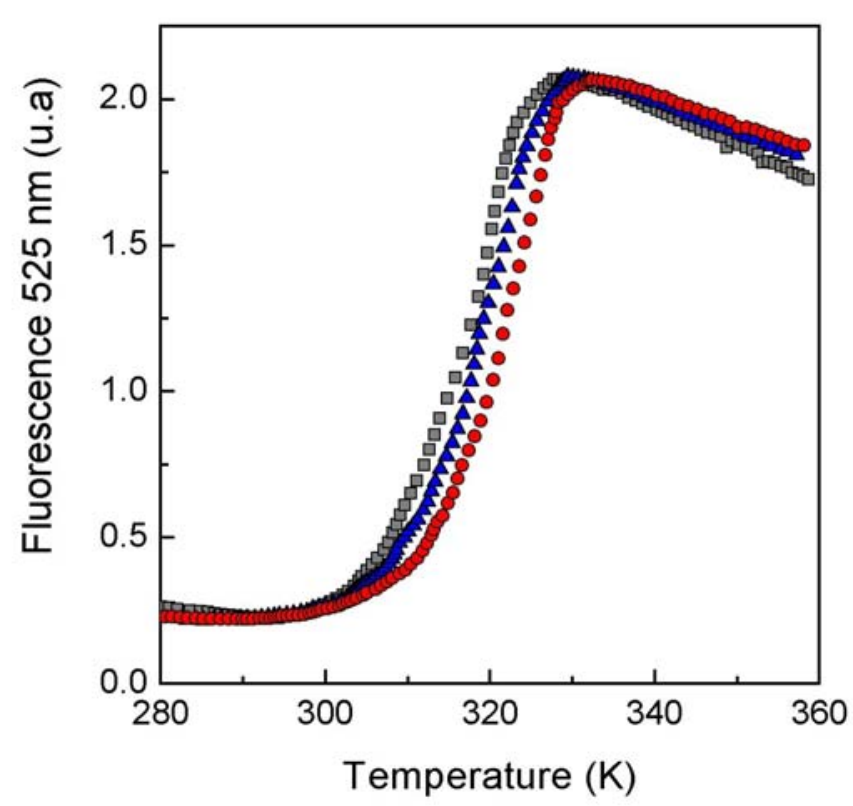

